OPEN ACCESS

Check for updates

\title{
Association between vitamin D supplementation and mortality: systematic review and meta-analysis
}

\author{
Yu Zhang, ${ }^{1}$ Fang Fang, ${ }^{2}$ Jingjing Tang, ${ }^{3}$ Lu Jia, ${ }^{4}$ Yuning Feng, ${ }^{1}$ Ping $X u,{ }^{5}$ Andrew Faramand ${ }^{6}$
}

${ }^{1}$ Affiliated Hospital of Chengdu University, Chengdu, Sichuan,

China

${ }^{2}$ West China Hospital, Sichuan

University, No 37, Guo Xue

Xiang, Chengdu, Sichuan

610041, China

${ }^{3}$ Chinese University of Hong

Kong, Shenzhen, Guangdong, China

${ }^{4}$ Shanxi Provincial People's Hospital, Taiyuan, Shanxi, China

${ }^{5}$ Sichuan University Library,

Chengdu, Sichuan, China

${ }^{6}$ University of Pittsburgh

Medical Centre, Pittsburgh,

PA, USA

Correspondence to: F Fang fangfang1057@outlook.com (ORCID 0000-0002-8711-1920)

Additional material is published online only. To view please visit the journal online.

Cite this as: $B M J$ 2019;366:14673 http://dx.doi.org/10.1136/bmj.l4673

Accepted: 5 July 2019

\section{ABSTRACT}

\section{OBJECTIVE}

To investigate whether vitamin D supplementation is associated with lower mortality in adults.

DESIGN

Systematic review and meta-analysis of randomised controlled trials.

\section{DATA SOURCES}

Medline, Embase, and the Cochrane Central Register from their inception to 26 December 2018.

\section{ELIGIBILITY CRITERIA FOR SELECTING STUDIES}

Randomised controlled trials comparing vitamin $D$ supplementation with a placebo or no treatment for mortality were included. Independent data extraction was conducted and study quality assessed. A metaanalysis was carried out by using fixed effects and random effects models to calculate risk ratio of death in the group receiving vitamin D supplementation and the control group.

MAIN OUTCOME MEASURES

All cause mortality.

RESULTS

50 trials with a total of 74655 participants were identified. Vitamin D supplementation was not associated with all cause mortality (risk ratio 0.98 , $95 \%$ confidence interval 0.95 to $1.02, \mathrm{I}^{2}=0 \%$ ), cardiovascular mortality $(0.98,0.88$ to $1.08,0 \%)$, or non-cancer, non-cardiovascular mortality $(1.05,0.93$ to $1.18,0 \%)$. Vitamin D supplementation statistically significantly reduced the risk of cancer death $(0.85$, 0.74 to $0.97,0 \%$ ). In subgroup analyses, all cause mortality was significantly lower in trials with vitamin $D_{3}$ supplementation than in trials with vitamin $D_{2}$ supplementation ( $P$ for interaction $=0.04$ ); neither vitamin $D_{3}$ nor vitamin $D_{2}$ was associated with a statistically significant reduction in all cause mortality.

CONCLUSIONS

Vitamin D supplementation alone was not associated with all cause mortality in adults compared with placebo or no treatment. Vitamin D supplementation

\section{WHAT IS ALREADY KNOWN ON THIS TOPIC}

Observational studies showed that low vitamin D levels were associated with increased mortality from life threatening conditions such as cancer and cardiovascular disease

Clinical data examining the effect of vitamin D supplementation on mortality reduction are inconsistent

\section{WHAT THIS STUDY ADDS}

Vitamin D supplementation alone was not associated with all cause mortality in adults compared with placebo or no treatment

Vitamin D supplementation reduced the risk of cancer death

reduced the risk of cancer death by $15 \%$. Additional large clinical studies are needed to determine whether vitamin $D_{3}$ supplementation is associated with lower all cause mortality.

STUDY REGISTRATION

PROSPERO registration number CRD42018117823.

\section{Introduction}

Vitamin D supplementation has been advocated for maintaining or even improving musculoskeletal health. Evidence from observational studies indicates that low vitamin D status is associated with higher mortality from life threatening conditions such as cancer and cardiovascular disease. ${ }^{12}$ Therefore, supplemental vitamin $\mathrm{D}$ has been viewed as a potential strategy for preventing non-skeletal chronic diseases. $^{3-5}$ If adequate vitamin $\mathrm{D}$ concentrations were to reduce risk of death from a wide variety of medical conditions, vitamin D supplementation would be a safe, economical, and widely available method to reduce mortality.

Clinical data examining the effect of vitamin D supplementation on mortality reduction are inconsistent. Observational studies have revealed an inverse association of vitamin $\mathrm{D}$ status and mortality..$^{6-9}$ Previous systemic reviews and metaanalyses of randomised controlled trials suggested that vitamin D supplementation has a small effect on total mortality. ${ }^{5} 10^{11}$ Interpretation of these reviews is difficult because they include trials of vitamin D administered with calcium, which has been associated with uncommon but important side effects (eg, cardiovascular events). ${ }^{12-15}$ Additionally, these reviews lack sufficient detail (eg, community versus institution settings), and trial sequential analysis showed that the pooled sample size failed to meet the optimum size. ${ }^{1011}$

Recently, additional trials ${ }^{16-32}$ assessing the effect of vitamin D supplementation on mortality have become available, which have approximately doubled the number of trial participants. Among these trials, the Vitamin D and Omega 3 Trial (VITAL) did not confirm the benefit of vitamin D supplementation on mortality. ${ }^{31}$ Because of the conflicting evidence, limitations of previous reviews, and availability of new data, we aimed to conduct a systematic review and meta-analysis of randomised controlled trials to evaluate the effect of vitamin D supplementation on all cause mortality.

\section{Methods}

Protocol and guidance

This study was performed in accordance with Preferred Reporting Items for Systematic Reviews and Meta- 
Analysis (PRISMA). ${ }^{33}$ The protocol for this review was registered with PROSPERO (CRD42018117823).

\section{Inclusion criteria}

We considered trials to be eligible if they enrolled adults (age $\geq 18$ ) with any health condition; if they compared vitamin D supplements at any dose with placebo or no treatment (when other agents were also given (eg, calcium), they had to be the same dosage in all groups); if they provided information on deaths from all causes (non-accidental) or any cause reported separately; and if they were randomised controlled trials (including quasi randomised and cluster randomised trials).

\section{Exclusion criteria}

We excluded studies if they were case reports, case series, or observational studies; if all the participants received vitamin $\mathrm{D}$; if they included pregnant or lactating women, or critically ill patients; if they used hydroxylated vitamin D or vitamin D analogues (which could differ from native vitamin D in effect and safety, including lower risk of fall ${ }^{34}$ and higher risk of hypercalcaemia ${ }^{1034}$ ).

\section{Outcomes}

The primary outcome was all cause mortality. Secondary outcomes were cancer mortality, cardiovascular mortality, non-cancer or non-cardiovascular mortality, cerebrovascular disease mortality, and ischaemic heart disease mortality. Supplemental eTable 1 shows the definitions of these outcomes.

\section{Search strategy}

One of the authors (PX) conducted the search of several databases: Medline(Ovid), Embase(Ovid), the Cochrane Central Register of Controlled Trials (CENTRAL), from inception to 26 December 2018. We also searched ClinicalTrials.gov and the World Health Organization International Clinical Trials Registry Platform to identify ongoing or unpublished eligible trials. To maximise the search for relevant articles, we reviewed reference lists of identified trials and systematic reviews. We did not apply language restrictions. Supplemental eTable 2 presents the search strategy.

\section{Study selection}

After removal of duplicates, two independent researchers (YZ and LJ) screened all titles and abstracts. They obtained full texts and performed further screening when studies were deemed eligible. Disagreements were resolved by consensus.

\section{Data collection process}

Two independent researchers (YZ and LJ) used a standard data extraction form to extract data from the included trials. When randomised controlled trials had more than two arms, we pooled data from the separate treatment arms. When a study mentioned an outcome of interest without providing estimates, we contacted the author for the data. Disagreements were resolved by consensus.
Assessment of risk of bias and quality of evidence Two researchers (YZ and LJ) independently assessed the quality of all included trials by using the Cochrane Collaboration risk of bias tool. ${ }^{35}$ They also examined the quality of evidence for outcomes using the grading of recommendations assessment, development, and evaluation (GRADE) approach. ${ }^{36}$

\section{Data synthesis}

We performed statistical analyses using RevMan (version 5.3.3; The Cochrane Collaboration) and the meta package in $\mathrm{R}$ (version 3.4.3; $\mathrm{R}$ Project for Statistical Computing). Analyses for all outcomes were conducted on an intention to treat basis. We used risk ratios and their associated 95\% confidence intervals to assess outcomes, and considered a $\mathrm{P}$ value less than 0.05 to be statistically significant. We assessed heterogeneity using the $\mathrm{I}^{2}$ test. ${ }^{37}$ If significant heterogeneity was not present $\left(\mathrm{I}^{2}<50 \%\right)$, we used fixed effects models to pool outcomes; we used random effects models when significant heterogeneity was present $\left(\mathrm{I}^{2} \geq 50 \%\right)$. The possibility of small study effects was assessed qualitatively by visual estimate of the funnel plot and quantitatively by calculation of the Egger test, the Begg test, and the Harbord test. ${ }^{38}$

\section{Trial sequential analysis}

We performed trial sequential analysis to explore whether cumulative data were adequately powered to evaluate outcomes. Trial sequential analysis (version 0.9.5.10) ${ }^{39}$ was used to maintain an overall $5 \%$ risk of type I error and $80 \%$ power. We initially anticipated an intervention effect of a $10 \%$ relative risk reduction for all cause mortality. In additional analyses, we used progressively smaller thresholds $(7.5 \%$ and $5 \%)$ until the optimum sample size exceeded the actual sample size.

\section{Subgroup analyses}

We performed several subgroup analyses to test interactions according to dose $(\geq 2000$ and $<2000 \mathrm{IU} /$ day); type of vitamin $\mathrm{D}$ (vitamin $\mathrm{D}_{2}$ and vitamin $\mathrm{D}_{3}$ ); timing of treatment (daily and intermittently); baseline 25 hydroxyvitamin $\mathrm{D}$ ( $\geq 50$ and $<50 \mathrm{nmol} / \mathrm{L}$ ); and mean age ( $\geq 70$ and $<70$ years). We conducted retrospective subgroup analyses based on length of follow-up (at least three years and less than three years); year of publication (before 2014 and in or after 2014); sex (female and both sexes); residential status (community and institution); bolus (yes and no); intervention (vitamin $\mathrm{D}$ and calcium with vitamin $\mathrm{D}$ ); and latitude $\left(\geq 40^{\circ}\right.$ and $\left.<40^{\circ}\right)$.

\section{Sensitivity analyses}

We conducted sensitivity analyses by excluding trials with high or unknown risk of bias; excluding trials with high risk or unknown risk of bias of the different domains; excluding quasi randomised or cluster randomised trials; excluding the largest trial; excluding trials with a follow-up of less than one year; using random effect models; adding trials that had 
been excluded for using vitamin D administered with calcium; adding trials that had been excluded for using hydroxylated vitamin D or vitamin D analogues; and using trial duration rather than long term follow-up.

\section{Patient and public involvement}

No patients were involved in setting the research question or the outcome measures, nor were they involved in developing plans for design or implementation of the study. No patients were asked to advise on interpretation or writing of results. The results will be disseminated to a wide audience, including members of the public, patients, health professionals, and experts in the specialty through social media and networks.

\section{Results}

\section{Eligible studies and study characteristics}

We initially identified 21425 records, and included 50 eligible trials ${ }^{16-32}$ 40-72 in the final meta-analysis (fig 1). Table 1 shows a summary of included trials and supplemental eTables 3 and 4 give details of those trials. The trials comprised 74655 participants, with 7993 all cause deaths, 1331 deaths from cardiovascular disease, 865 deaths from cancer, and 1045 deaths from non-cancer, non-cardiovascular disease. Supplemental eTable 5 summarises the details of three large ongoing randomised trials.

Supplemental eFigures 1 and 2 show risk of bias. Twenty trials had a low risk of bias, 18 trials had an unclear risk, and 12 trials had a high risk of bias. Using the GRADE summary of evidence, the quality of evidence for the primary outcome was high (supplemental eTable 6).

\section{Primary outcome: all cause mortality}

All 50 trials reported all cause mortality. There was no statistically significant difference in all cause mortality between the vitamin $\mathrm{D}$ supplementation group and the control group (risk ratio 0.98, 95\% confidence interval 0.95 to $1.02, \mathrm{I}^{2}=0 \%$; fig 2). In trial sequential analysis, the information size of all cause mortality met the required size of $10 \%$ and $7.5 \%$ relative risk reduction; however, futility was not reached in our additional trial sequential analysis with $5 \%$ relative risk reduction (supplemental eFigures 3-5). Funnel plot analysis showed no asymmetry (supplemental eFigure 6); additionally the Egger test $(\mathrm{P}=0.50)$, Begg test $(\mathrm{P}=0.20)$, and Harbord test $(\mathrm{P}=0.36)$ detected no significant small study effects. The meta-analysis results for all cause mortality were robust in sensitivity analyses (supplemental eTable 7).

Subgroup analyses found that all cause mortality was significantly lower among trials with vitamin $\mathrm{D}_{3}$ supplementation than in trials with vitamin $\mathrm{D}_{2}$ supplementation ( $P$ for interaction $=0.04$; table 2 ), although neither group was associated with all cause mortality. Meta-regressions found that all cause mortality was significantly lower in trials with longer follow-up ( $\mathrm{P}$ for interaction=0.04; supplemental eFigures 9 and 10).

\section{Secondary outcome: other mortality}

Vitamin D supplementation was associated with significant reduction in cancer mortality (risk ratio 0.85 , 95\% confidence interval 0.74 to $0.97, \mathrm{I}^{2}=0 \%$; fig 3). However, benefit was only seen in participants receiving vitamin $\mathrm{D}_{3}$ supplementation, and no participants received vitamin D2 supplementation (supplemental eTable 8). We found no statistically significant difference between groups in cardiovascular mortality $(0.98,0.88$ to $1.08, \mathrm{I}^{2}=0 \%$ ) or non-cancer, non-cardiovascular mortality $\left(1.05,0.93\right.$ to $\left.1.18, \mathrm{I}^{2}=0 \%\right)$. Vitamin D supplementation did not reduce the risk of death from cerebrovascular disease $\left(1.04,0.84\right.$ to $1.29, \mathrm{I}^{2}=0 \%$; supplemental eTable7) or ischaemic heart disease (0.96, 0.81 to $1.15, \mathrm{I}^{2}=0 \%$; supplemental eTable 8).

\section{Discussion}

In this meta-analysis of 50 randomised controlled trials with a total of 74655 participants, vitamin D supplementation was not significantly associated with total mortality (risk ratio 0.98, 95\% confidence interval 0.95 to 1.02). The findings suggest that vitamin D supplementation reduced cancer mortality by $15 \%$ (95\% confidence interval 0.74 to 0.97 ), but not mortality from cardiovascular disease, cerebrovascular disease, or ischaemic heart disease.

\section{Principal findings and comparison with other studies}

The results of this study on all cause mortality differ from two previous systematic reviews. ${ }^{51011}$ A Cochrane review in 2014 found that vitamin D supplementation decreased all cause mortality in analyses of 56 trials with a total of 95286 participants (relative risk 0.97 , $95 \%$ confidence interval 0.94 to $0.99, \mathrm{P}=0.02) .{ }^{10} \mathrm{In}$ the same year, a systematic review by Bolland and colleagues that included 40 trials with a total of 81173 participants also suggested a small effect on all cause mortality $(0.96,0.93$ to $1.00, \mathrm{P}=0.04) .{ }^{11}$ The previous reviews probably reached more optimistic conclusions as a result of different selection criteria and newly published trials. Compared with these reviews, ${ }^{10}{ }^{11}$ we excluded more than 10 trials totalling approximately 50000 participants of vitamin D administered with calcium, six trials ${ }^{73-79}$ of hydroxylated vitamin D or vitamin D analogues, and one trial ${ }^{80}$ retracted in 2017. To determine whether the null finding was driven by excluding trials which had been included in previous reviews, we performed two sensitivity analyses by adding trials that were originally excluded, and confirmed the results of the overall analysis. Moreover, this study additionally included 17 randomised controlled trials ${ }^{16-32}$ published after 2014, so that the more recent trials accounted for 50.3\% (37568/ 74655) of the total number of participants.

In contrast to the results for total mortality, this study found that vitamin D supplementation reduced cancer mortality by $15 \%$. The results of previous reviews on cancer mortality have been inconsistent. In 2014, a Cochrane review by Bjelakovic and colleagues presented low quality evidence that vitamin D supplementation 


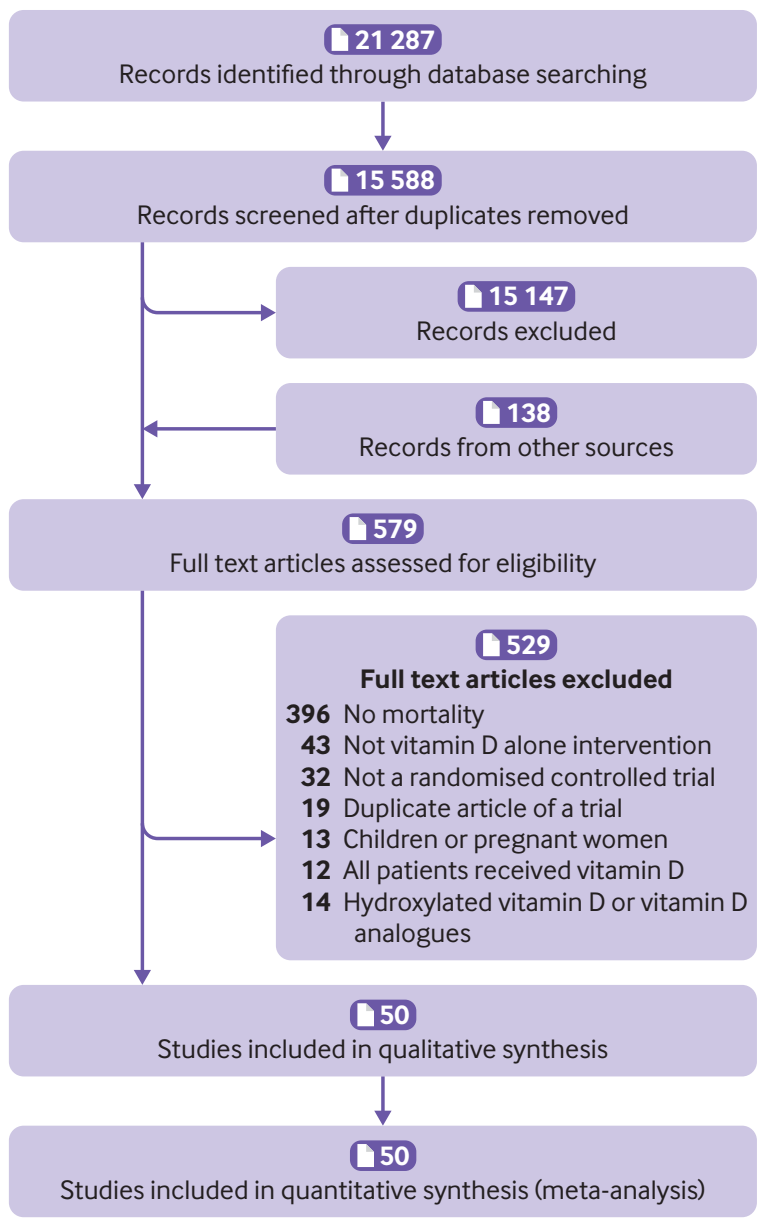

Fig 1 | Search strategy and final included and excluded studies

resulted in a decrease in cancer mortality (relative risk $0.88,95 \%$ confidence interval 0.78 to 0.98 ), but suggested that the required information size was not reached.$^{81}$ In parallel, two systematic reviews published similar results. ${ }^{1182}$ However, their meta-analyses were limited by the number of trials $(n \leq 4)$, administration of a generally low dose of vitamin D ( $\leq 1100 \mathrm{IU} /$ day), and mixed interventions (vitamin D plus calcium). In 2018,

\begin{tabular}{ll}
\hline \multicolumn{2}{l}{ Table 1 | Summary characteristics of included studies } \\
\begin{tabular}{ll} 
Characteristics & No of trials (No of participants) \\
Eligible studies: & $50(74655)$ \\
\hline Total No of trials (No of participants) & $1.0(0.7-3.0)$ \\
\hline Median (IQR) follow-up (years) & $12(57818)$ \\
\hline Follow-up at least three years & $251(125-839)$ \\
\hline Median (IQR) No of participants & 7993 \\
\hline Total No of deaths & $64(40-100)$ \\
\hline Median (IQR) \% female & $74(65-80)$ \\
\hline Median (IQR) age (years) & $29(32840)$ \\
\hline Country: & $10(31240)$ \\
\hline European & $10(10057)$ \\
\hline American & $1(518)$ \\
\hline Asian-Pacific & $4(886)$ \\
\hline International country & $21(15194)$ \\
\hline Baseline 25 hydroxyvitamin D (nmol/L): & $16(24408)$ \\
\hline$<25$ & $2(26058)$ \\
\hline $25-50$ &
\end{tabular} \\
\hline $50-75$ & \\
\hline$>75$ & \\
\hline
\end{tabular}

a meta-analysis by Goulão and colleagues did not find evidence to suggest that vitamin D supplementation alone reduced cancer mortality (1.03, 0.91 to 1.15$){ }^{83}$ After we submitted our current study for initial review by The $B M J$, an additional meta-analysis by Keum and colleagues was published. ${ }^{84}$ Their review found that vitamin D supplementation significantly reduced cancer mortality $(0.87,0.79$ to 0.96$){ }^{84}$ Our findings on cancer mortality are consistent with those of Keum and colleagues, but some of the methods used in the two studies differ. The study by Keum and colleagues included trials of hydroxylated vitamin D, vitamin D analogues, and vitamin D administered with calcium, which were excluded in our study. Moreover, our study provided absolute and relative risks, evaluated the quality of the evidence by using the GRADE approach, and explored the optimum sample size with trial sequential analysis. More importantly, our study found that reduced cancer mortality was only seen with vitamin $\mathrm{D}_{3}$ supplementation, not with vitamin $\mathrm{D}_{2}$ supplementation.

An important finding from our subgroup analysis was that the effect of vitamin D differs for vitamin $\mathrm{D}_{2}$ and $\mathrm{D}_{3}$ supplementation. We found that all cause mortality was significantly lower among trials with vitamin $\mathrm{D}_{3}$ supplementation than in trials with vitamin $\mathrm{D}_{2}$ supplementation; however neither supplement was associated with statistically significant reduced risk. Similarly, vitamin $\mathrm{D}_{3}$ supplementation reduced the risk of cancer mortality, but vitamin $\mathrm{D}_{2}$ did not. The different effect on mortality of vitamin $\mathrm{D}_{2}$ and $\mathrm{D}_{3}$ might be explained by the diverse effect on raising 25 hydroxyvitamin D concentrations. Historically, vitamin $\mathrm{D}_{2}$ and vitamin $\mathrm{D}_{3}$ were considered to be equally effective at raising 25 hydroxyvitamin D concentrations. Currently, the comparative efficacy of vitamins $D_{2}$ and $D_{3}$ has been investigated in several intervention trials, with most indicating that vitamin $\mathrm{D}_{3}$ increases 25 hydroxyvitamin $\mathrm{D}$ concentrations more efficiently than vitamin $\mathrm{D}_{2} \cdot{ }^{8586} \mathrm{~A}$ Cochrane review in 2014 found that vitamin $\mathrm{D}_{3}$ seemed to reduce total mortality (risk ratio 0.94, 95\% confidence interval 0.91 to 0.98 ), whereas vitamin $\mathrm{D}_{2}$ had no statistically significant beneficial effects on total mortality (1.02, 0.96 to 1.08). ${ }^{10}$ However, the Cochrane review did not reveal heterogeneity between vitamin $D_{2}$ and $D_{3}$. Therefore, we should be cautious about the strength of the evidence that vitamin $\mathrm{D}_{3}$ reduced all cause mortality $(0.95,0.91$ to1.00, $\mathrm{P}=0.07)$.

Vitamin $\mathrm{D}_{3}$ is the most widely used type of vitamin D supplementation and has a clinically relevant effect of reducing all cause mortality by $5 \%$, with the $\mathrm{P}$ value and 95\% confidence interval close to the level of formal statistical significance. The current study is not a positive study, but it is also not an unambiguously negative study. In addition, subgroup analyses are observational by nature and are not based on randomised comparisons. ${ }^{87}$ Therefore, the effect of vitamin $\mathrm{D}_{3}$ on all cause mortality requires additional evidence, preferably gathered by future large randomised controlled trials. 


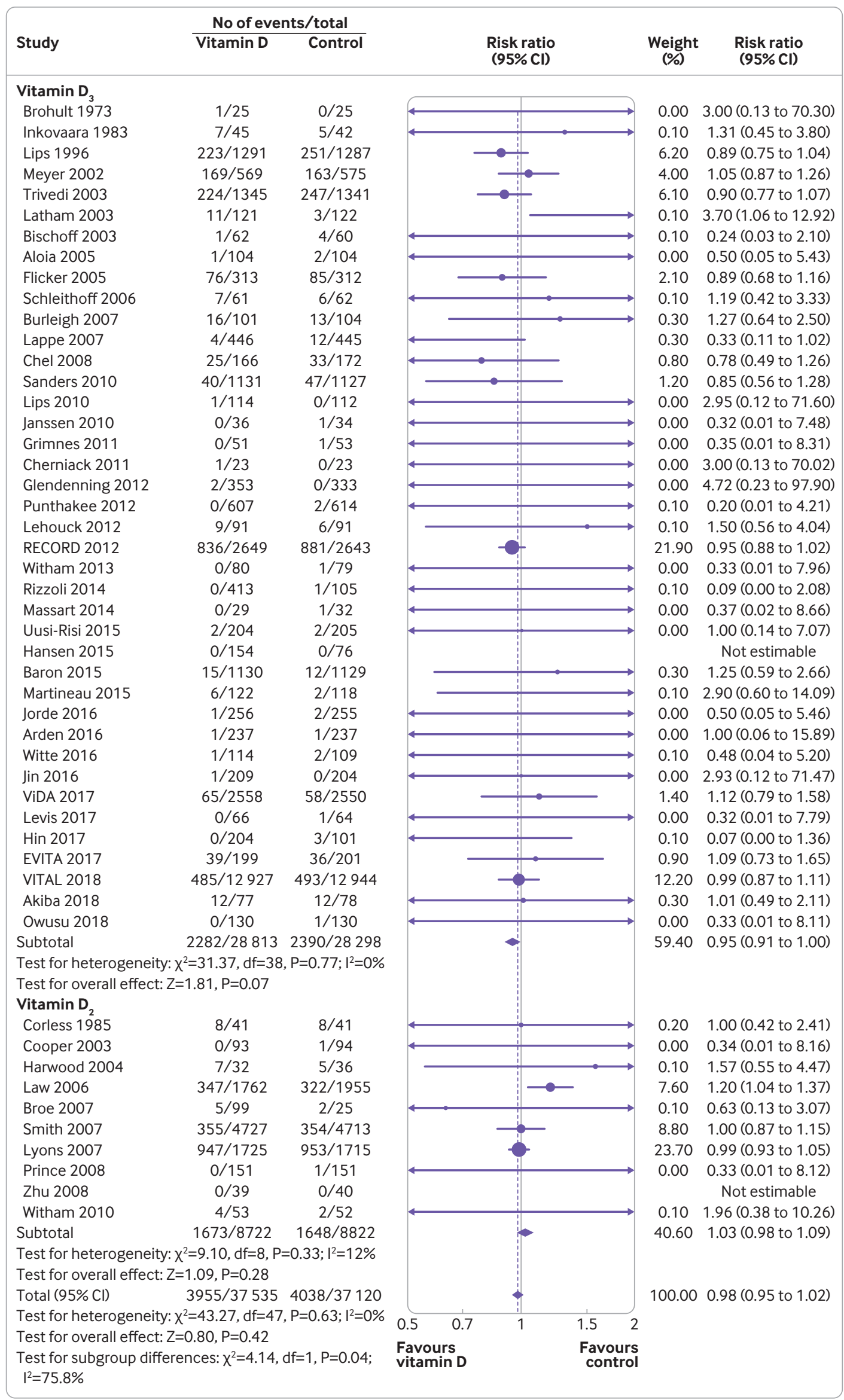

Fig 2 | Forest plot of all cause mortality of trials evaluating vitamin $D_{3}$ and vitamin $D_{2}$ supplementation 


\begin{tabular}{|c|c|c|c|c|c|}
\hline Subgroup title & No of trials & No of participants & $I^{2}(\%)$ & Risk ratio $(95 \% \mathrm{Cl})$ & $P$ for interaction \\
\hline Overall & 50 & 74655 & 0 & 0.98 (0.95 to 1.02$)$ & - \\
\hline \multicolumn{6}{|l|}{ No of participants: } \\
\hline$\geq 2000$ & 11 & 63793 & 24 & $0.99(0.95$ to 1.03$)$ & \multirow{2}{*}{0.65} \\
\hline$<2000$ & 39 & 10862 & 0 & $0.95(0.81$ to 1.11$)$ & \\
\hline \multicolumn{6}{|l|}{ No of events: } \\
\hline$\geq 200$ & 8 & 54168 & 0 & 0.99 (0.95 to 1.03$)$ & \multirow{2}{*}{0.85} \\
\hline$<200$ & 42 & 20487 & 0 & $0.97(0.85$ to 1.11$)$ & \\
\hline \multicolumn{6}{|l|}{ Age (years): } \\
\hline$\geq 70$ & 22 & 39390 & 0 & $1.00(0.90$ to 1.11$)$ & \multirow{2}{*}{0.78} \\
\hline$<70$ & 28 & 35265 & 17 & 0.98 (0.94 to 1.02$)$ & \\
\hline \multicolumn{6}{|l|}{ Sex: } \\
\hline Female & 14 & 17671 & 20 & 0.95 (0.86 to 1.05$)$ & \multirow{2}{*}{0.47} \\
\hline Male and female & 36 & 56984 & 0 & $0.99(0.95$ to 1.03$)$ & \\
\hline \multicolumn{6}{|c|}{ Baseline mean 25 hydroxyvitamin D (nmol/L): } \\
\hline$\geq 50$ & 18 & 50466 & 0 & 1.04 (0.97 to 1.12$)$ & \multirow{2}{*}{0.07} \\
\hline$<50$ & 26 & 16080 & 19 & 0.95 (0.90 to 1.01$)$ & \\
\hline \multicolumn{6}{|l|}{ Year of publication: } \\
\hline Before 2014 & 33 & 37088 & 5 & $0.98(0.94$ to 1.02$)$ & \multirow{2}{*}{0.77} \\
\hline In or after 2014 & 17 & 37567 & 0 & $1.00(0.90$ to 1.11$)$ & \\
\hline \multicolumn{6}{|l|}{ Type of vitamin D: } \\
\hline Vitamin $\mathrm{D}_{3}$ & 40 & 57111 & 0 & 0.95 (0.91 to 1.00$)$ & \multirow{2}{*}{$0.04^{*}$} \\
\hline Vitamin $\mathrm{D}_{2}$ & 10 & 17544 & 12 & 1.03 (0.98 to 1.09$)$ & \\
\hline \multicolumn{6}{|l|}{ Daily dose equivalent (IU): } \\
\hline$<2000$ & 30 & 39785 & 0 & 0.98 (0.94 to 1.02$)$ & \multirow{2}{*}{0.56} \\
\hline$\geq 2000$ & 16 & 34116 & 0 & $1.01(0.91$ to 1.13$)$ & \\
\hline \multicolumn{6}{|l|}{ Timing: } \\
\hline Daily & 31 & 47931 & 0 & $0.99(0.94$ to 1.04$)$ & \multirow{2}{*}{0.79} \\
\hline Intermittently & 15 & 25815 & 0 & 0.98 (0.93 to 1.03$)$ & \\
\hline \multicolumn{6}{|l|}{ Bolus or not: } \\
\hline Bolus & 10 & 24612 & 0 & $0.98(0.93$ to 1.04$)$ & \multirow{2}{*}{1.00} \\
\hline Non-bolus & 36 & 49134 & 0 & 0.98 (0.93 to 1.04) & \\
\hline \multicolumn{6}{|l|}{ Residential status: } \\
\hline Community & 41 & 62362 & 0 & $0.97(0.92$ to 1.02$)$ & \multirow{2}{*}{0.31} \\
\hline Institution & 9 & 12293 & 0 & 1.01 (0.96 to 1.06$)$ & \\
\hline \multicolumn{6}{|l|}{ Follow-up: } \\
\hline At least three years & 12 & 57818 & 0 & 0.97 (0.93 to 1.01$)$ & \multirow{2}{*}{0.26} \\
\hline Less than three years & 38 & 16837 & 6 & $1.02(0.95$ to 1.11$)$ & \\
\hline Intervention: & & & & & \\
\hline Vitamin D & 34 & 62767 & 0 & $1.00(0.96$ to 1.05$)$ & 0.08 \\
\hline Vitamin D plus calcium & 16 & 11888 & 0 & $0.93(0.87$ to 1.00$)$ & \\
\hline Latitude: & & & & & \\
\hline$\geq 40^{\circ}$ & 36 & 41002 & 5 & 0.99 (0.95 to 1.03$)$ & 0.71 \\
\hline$<40^{\circ}$ & 13 & 33135 & 0 & 0.97 (0.87 to 1.08$)$ & \\
\hline
\end{tabular}

A further important finding from meta-regression was that all cause mortality was statistically significantly lower in trials with longer follow-up. Sensitivity analysis found a potential effect of vitamin D supplementation on all cause mortality after trials with a follow-up of less than one year were excluded (risk ratio 0.97, 95\% confidence interval 0.93 to 1.00). However, subgroup analysis did not find a statistically significant difference in the effect of vitamin D supplementation on mortality in trials with a follow-up of less than three years and more than three years $(P=0.26)$. Additionally, the previous meta-analysis did not find a subgroup difference according to the length of follow-up. ${ }^{1011}$

The VITAL trial reported increasing benefit over time. ${ }^{31}$ Although no significant differences relate to cancer mortality (risk ratio $0.83,95 \%$ confidence interval 0.67 to 1.02 ) or all cause mortality (0.99, 0.87 to 1.12), after excluding the first one and two years of follow-up, the risk ratio was significantly reduced to 0.75 for cancer mortality ( $95 \%$ confidence interval
0.59 to 0.96 ) and was slightly reduced to 0.96 for all cause mortality (0.84 to 1.11$)$. Therefore, the length of follow-up could modify the effect of vitamin D supplementation on all cause mortality.

\section{Strengths and limitations}

This systematic review and meta-analysis has several methodological strengths. We followed the recommendations of the Cochrane Collaboration and PRISMA statement, including a priori protocol. This study also included a rigorous assessment of the quality of evidence using the GRADE approach (the quality for the primary outcome was high) and of the minimum information size required in trial sequential analysis (the study met the optimum size).

Our study has important limitations. The study was based solely on published trials that reported mortality outcomes. However, most trials of vitamin D supplementation did not report mortality, which suggests that substantial selective reporting was likely. Also, 


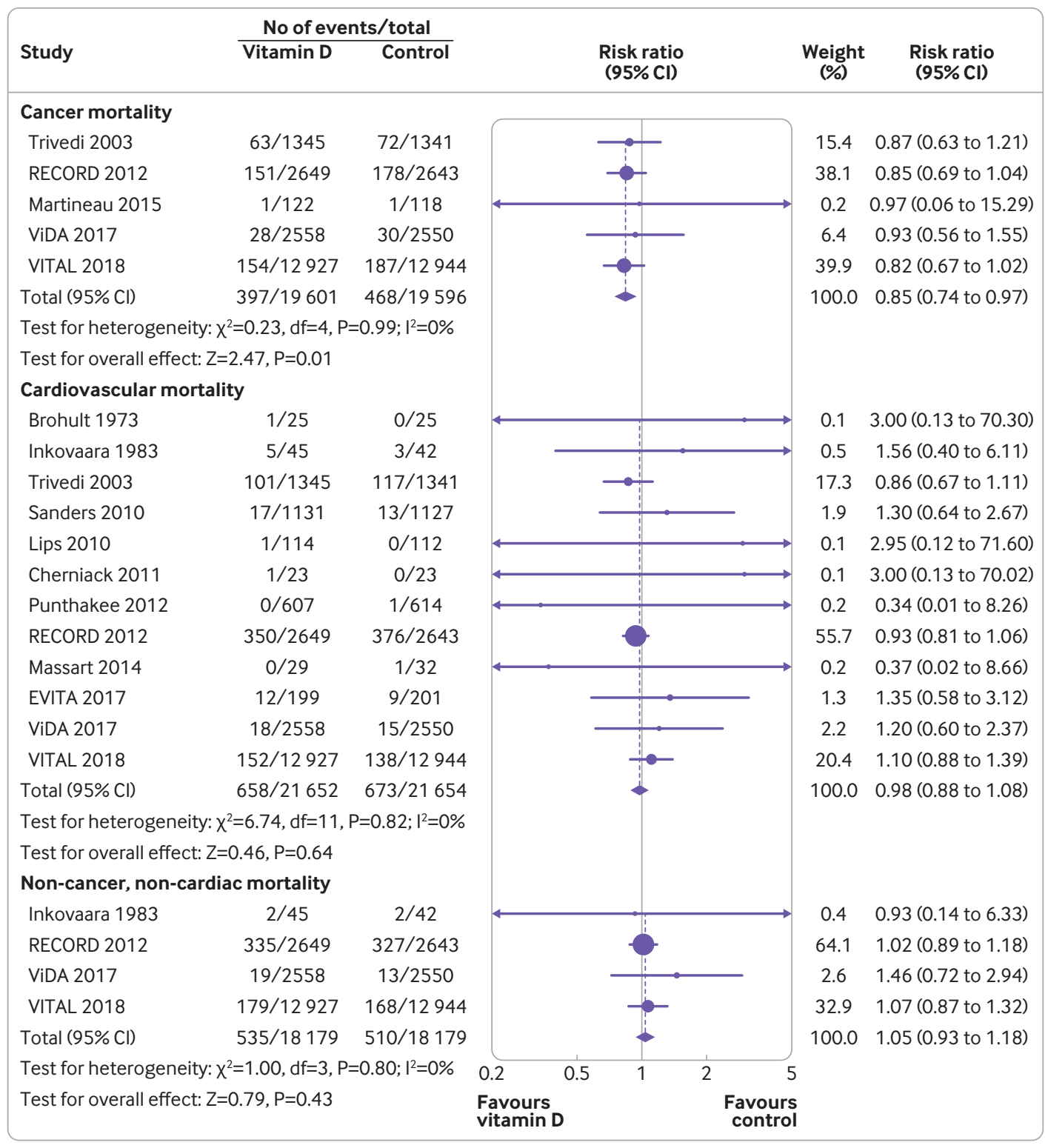

Fig 3 | Forest plot of cancer mortality, cardiovascular mortality, and non-cancer, non-cardiovascular mortality of trials evaluating vitamin D supplementation

all cause mortality reported among all included trials was the secondary outcome of the trials. Data for this secondary outcome might have been collected differently than data for the primary outcome in the trials.

Most included trials allowed personal supplementation with low dose vitamin D in the control group. In the VITAL trial, ${ }^{31}$ for example, $42.5 \%$ of participants in the control group used vitamin D supplementation $(\leq 800 \mathrm{IU} /$ day). The high prevalence of vitamin D supplementation in the control group made it more difficult to distinguish between the treatment and control groups.

The dose of vitamin D used in included trials varied. Our study could not accurately compare equivalent daily vitamin $\mathrm{D}$ supplementation dose in the included trials because they all had different treatment regimens and dosing intervals (daily, weekly, monthly, or bolus doses). This might be one of the reasons why this study did not determine an effective daily dose of vitamin D supplementation. Furthermore, the vitamin D status before, during, and after treatment is useful to determine the effectiveness of vitamin D supplementation in improving the actual vitamin D status. Long term vitamin D status is expected to be a much more accurate, reliable, and important clinical parameter compared with a daily dose of vitamin D supplementation. However, previous trials were limited in providing such data. These limitations and uncertainties associated with vitamin D supplementation dose and vitamin D status in treatment and control groups warrant further investigation.

The baseline 25 hydroxyvitamin D concentrations of trial participants have not been low enough, which could partly contribute to the null finding on the association of vitamin D supplementation and all cause 
mortality. Observational studies have indicated an increased mortality risk only at low 25 hydroxyvitamin D concentrations. An individual participant data meta-analysis of observational studies showed that the adjusted hazard ratio (95\% confidence interval) for mortality in the 25 hydroxyvitamin D groups with concentrations less than 30, 30-40, and 40-50 nmol/L were 1.67 (1.44 to 1.89 ), 1.33 (1.16 to 1.51 ), and 1.15 (1.00 to 1.29 ), respectively, compared with participants with 25 hydroxyvitamin D concentrations of 75-100 nmol/L. ${ }^{8}$ In this study, more than half of participants (50466/ 66546) from trials reported a baseline mean 25 hydroxyvitamin D concentration of more than $50 \mathrm{nmol} / \mathrm{L}$.

\section{Implications}

Mortality is the most important clinical outcome. Our study size met the optimum sample size of $7.5 \%$ relative risk reduction and the pooled risk ratio was close to 1 with a narrow confidence interval. Our findings suggest that vitamin $\mathrm{D}$ supplementation did not have a clinically relevant effect on all cause mortality, and so there is little evidence that vitamin D supplementation reduces all cause mortality. However, vitamin D supplementation reduced cancer mortality by $15 \%$. Therefore, this analysis supports the concept that the risk of cancer death could be reduced by vitamin $\mathrm{D}$ supplementation, and a more targeted intervention for this role might be appropriate.

The current study found that all cause mortality was significantly lower among trials with vitamin $\mathrm{D}_{3}$ supplementation than in trials with vitamin $\mathrm{D}_{2}$ supplementation, with a trend towards reduced all cause mortality in those taking vitamin $\mathrm{D}_{3}(\mathrm{P}=0.07)$. Similarly, vitamin $\mathrm{D}_{3}$ supplementation reduced the risk of cancer death, but vitamin $\mathrm{D}_{2}$ did not. Another finding from subgroup analysis suggested that all cause mortality was significantly lower in trials with longer follow-up, and that the benefit of reduced cancer mortality was seen in trials with longer follow-up (more than three years) but not in those with a shorter followup. According to these findings, supplementation with vitamin $\mathrm{D}_{3}$ for at least three years should be considered. Additional large randomised controlled trials are needed to confirm the results from our subgroup analyses.

Several large ongoing trials have the potential to corroborate or refute our findings. In the D-Health trial (Australian New Zealand Clinical Trials Registry: ACTRN12613000743763), high dose vitamin D supplementation (60000 IU/month) is being used to prevent mortality and cancer in Australian adults aged 60-79. The D-Health trial recently completed the recruitment of almost 21315 participants, with a minimum of five years of follow-up. Using a similar study design, the VIDAL trial (Vitamin D and Longevity trial; ISRCTN46328341) is analysing the effect of intermittent high dose vitamin D supplementation (60000IU/month) on all cause mortality in adults aged 65-84 with a corrected serum calcium level of $2.65 \mathrm{mmol} / \mathrm{L}$. The DO-HEALTH trial (Vitamin D3-
Omega3-Home Exercise-Healthy Ageing and Longevity Trial; ClinicalTrials.gov identifier: NCT01745263) has recruited 2152 participants from five European countries aged 70 years and older. The specific aim is to establish whether vitamin D will prevent disease at an older age. The final results of the DO-HEALTH trial will be available in autumn 2019. Although none of these trials have screened for low baseline 25 hydroxyvitamin D for eligibility, all trials have used vitamin $\mathrm{D}_{3}$ as the intervention.

\section{Conclusions}

Overall, vitamin D supplementation was not associated with all cause mortality, cardiovascular mortality, or non-cancer, non-cardiovascular mortality in adults. However, vitamin D supplementation was associated with a reduced risk of cancer mortality by $15 \%$. There was a trend towards reduced all cause mortality with vitamin $\mathrm{D}_{3}$ supplementation, which warrants further investigation.

We thank L Dade Lunsford (University of Pittsburgh Medical Centre), Jing Li (West China Hospital), and Huiwen Tan (West China Hospital) for their support in preparing the final draft of this paper.

Contributors: FF and $\mathrm{YZ}$ conceived the study and designed the protocol. PX performed the literature search. YZ and LJ selected the studies and extracted the relevant information. JT, YF, and YZ synthesised the data. $Y Z$ wrote the first draft of the paper. All authors critically revised successive drafts of the paper and approved the final version. FF and $\mathrm{YZ}$ are the study guarantors. The corresponding author attests that all listed authors meet authorship criteria and that no others meeting the criteria have been omitted.

Funding: This work is supported by the projects of the National Natural Science Foundation of China (No 81100925 and No 81472361) and by the National Key R\&D Program of China (No 2018YFA010860004). The funders of the study had no role in study design, data collection, data analysis, data interpretation, or writing of the report.

Competing interests: All authors have completed the ICMJE uniform disclosure form at www.icmje.org/coi_disclosure.pdf and declare: support from the National Natural Science Foundation of China and the National Key R\&D Program of China; no financial relationships with any organisations that might have an interest in the submitted work in the previous three years; no other relationships or activities that could appear to have influenced the submitted work.

Ethical approval: Not required.

Data sharing: Additional data available from the corresponding author at fangfang1057@outlook.com.

The lead author (FF) affirms that this manuscript is an honest, accurate, and transparent account of the study being reported; that no important aspects of the study have been omitted; and that any discrepancies from the study as planned (and, if relevant, registered) have been explained.

This is an Open Access article distributed in accordance with the Creative Commons Attribution Non Commercial (CC BY-NC 4.0) license, which permits others to distribute, remix, adapt, build upon this work non-commercially, and license their derivative works on different terms, provided the original work is properly cited and the use is noncommercial. See: http://creativecommons.org/licenses/by-nc/4.0/.

1 Chowdhury R, Kunutsor S, Vitezova A, et al. Vitamin D and risk of cause specific death: systematic review and meta-analysis of observational cohort and randomised intervention studies. BMJ 2014;348:g1903. doi:10.1136/bmj.g1903

2 Wang TJ. Vitamin D and cardiovascular disease. Annu Rev Med 2016;67:261-72. doi:10.1146/annurev-med-051214-025146 3 Grandi NC, Breitling LP, Vossen CY, et al. Serum vitamin D and risk of secondary cardiovascular disease events in patients with stable coronary heart disease. Am Heart J 2010;159:1044-51. doi:10.1016/j.ahj.2010.03.031

4 Yin L, Ordóñez-Mena JM, Chen T, Schöttker B, Arndt V, Brenner $\mathrm{H}$. Circulating 25-hydroxyvitamin D serum concentration and total cancer incidence and mortality: a systematic review and 
meta-analysis. Prev Med 2013;57:753-64. doi:10.1016/j. ypmed.2013.08.026

5 Autier P, Mullie P, Macacu A, et al. Effect of vitamin D supplementation on non-skeletal disorders: a systematic review of meta-analyses and randomised trials. Lancet Diabetes Endocrinol 2017;5:986-1004. doi:10.1016/S2213-8587(17)30357-1

6 Johansson H, Odén A, Kanis J, et al. Low serum vitamin D is associated with increased mortality in elderly men: MrOS Sweden. Osteoporos Int 2012;23:991-9. doi:10.1007/s00198-011-1809-5

7 Zittermann A, lodice S, Pilz S, Grant WB, Bagnardi V, Gandini S. Vitamin D deficiency and mortality risk in the general population: a meta-analysis of prospective cohort studies. Am J Clin Nutr 2012;95:91-100. doi:10.3945/ajcn.111.014779

8 Gaksch M, Jorde R, Grimnes G, et al. Vitamin D and mortality: individual participant data meta-analysis of standardized 25-hydroxyvitamin D in 26916 individuals from a European consortium. PLoS One 2017;12:e0170791. doi:10.1371/journal. pone.0170791

9 Durazo-Arvizu RA, Dawson-Hughes B, Kramer $\mathrm{H}$, et al. The reverse J-shaped association between serum total 25-hydroxyvitamin D concentration and all-cause mortality: the impact of assay standardization. Am J Epidemiol 2017;185:720-6. doi:10.1093/aje/ kww244

10 Bjelakovic G, Gluud LL, Nikolova D, et al. Vitamin D supplementation for prevention of mortality in adults. Cochrane Database Syst Rev 2014;(1):CD007470. doi:10.1002/14651858.CD007470. pub3

11 Bolland MJ, Grey A, Gamble GD, Reid IR. The effect of vitamin D supplementation on skeletal, vascular, or cancer outcomes: a trial sequential meta-analysis. Lancet Diabetes Endocrinol 2014;2:307. 20. doi:10.1016/S2213-8587(13)70212-2

12 Anderson JL, May HT, Horne BD, et al, Intermountain Heart Collaborative (IHC) Study Group. Relation of vitamin D deficiency to cardiovascular risk factors, disease status, and incident events in a general healthcare population. Am J Cardiol 2010;106:963-8. doi:10.1016/j.amjcard.2010.05.027

13 Bolland MJ, Avenell A, Baron JA, et al. Effect of calcium supplements on risk of myocardial infarction and cardiovascular events: metaanalysis. BMJ 2010;341:c3691. doi:10.1136/bmj.c3691

14 Lewis JR, Zhu K, Prince RL. Adverse events from calcium supplementation: relationship to errors in myocardial infarction selfreporting in randomized controlled trials of calcium supplementation. I Bone Miner Res 2012;27:719-22. doi:10.1002/jbmr.1484

15 Bolland MJ, Grey A, Avenell A, Gamble GD, Reid IR. Calcium supplements with or without vitamin D and risk of cardiovascular events: reanalysis of the Women's Health Initiative limited access dataset and meta-analysis. BMJ 2011;342:d2040. doi:10.1136/ bmj.d2040

16 Massart A, Debelle FD, Racapé J, et al. Biochemical parameters after cholecalciferol repletion in hemodialysis: results grom the VitaDial randomized trial. Am J Kidney Dis 2014;64:696-705. doi:10.1053/j. ajkd.2014.04.020

17 Rizzoli R, Dawson-Hughes B, Kaufman JM, et al. Correction of vitamin $D$ insufficiency with combined strontium ranelate and vitamin D3 in osteoporotic patients. Eur J Endocrinol 2014;170:441-50. doi:10.1530/EJE-13-0775

18 Baron JA, Barry EL, Mott LA, et al. A trial of calcium and vitamin $\mathrm{D}$ for the prevention of colorectal adenomas. N Engl J Med 2015:373:1519-30 doi:10.1056/NEIMoa1500409

19 Hansen KE, Johnson RE, Chambers KR, et al. Treatment of vitamin $D$ insufficiency in postmenopausal women: a randomized clinical trial. JAMA Intern Med 2015;175:1612-21. doi:10.1001/ jamainternmed 2015.3874

20 Martineau AR, James WY, Hooper RL, et al. Vitamin D3 supplementation in patients with chronic obstructive pulmonary disease (ViDiCO): a multicentre, double-blind, randomised controlled trial. Lancet Respir Med 2015;3:120-30. doi:10.1016/S22132600(14)70255-3

21 Uusi-Rasi K, Patil R, Karinkanta S, et al. Exercise and vitamin D in fall prevention among older women: a randomized clinical trial. JAMA Intern Med 2015;175:703-11. doi:10.1001/ jamainternmed.2015.0225

22 Arden NK, Cro S, Sheard S, et al. The effect of vitamin D supplementation on knee osteoarthritis, the VIDEO study: a randomised controlled trial. Osteoarthritis Cartilage 2016;24:185866. doi:10.1016/i.joca.2016.05.020

23 Jin X, Jones G, Cicuttini F, et al. Effect of vitamin D supplementation on tibial cartilage volume and knee pain among patients with symptomatic knee osteoarthritis: a randomized clinical trial. JAMA 2016:315:1005-13. doi:10.1001/jama.2016.1961

24 Jorde R, Sollid ST, Svartberg J, et al. Vitamin D 20,000 IU per week for five years does not prevent progression from prediabetes to diabetes. J Clin Endocrinol Metab 2016;101:1647-55. doi:10.1210/ jc. $2015-4013$
25 Witte KK, Byrom R, Gierula J, et al. Effects of vitamin D on cardiac function in patients with chronic HF: the VINDICATE study. I Am Coll Cardiol 2016;67:2593-603 doi:10.1016/j.jacc.2016.03.508

26 Hin H, Tomson J, Newman C, et al. Optimum dose of vitamin D for disease prevention in older people: BEST-D trial of vitamin D in primary care. Osteoporos Int 2017;28:841-51. doi:10.1007/ s00198-016-3833-y

27 Levis S, Gómez-Marín O. Vitamin D and physical function in sedentary older men. J Am Geriatr Soc 2017;65:323-31. doi:10.1111/ jgs. 14510

28 Scragg R, Stewart AW, Waayer D, et al. Effect of monthly highdose vitamin D supplementation on cardiovascular disease in the vitamin D assessment study: a randomized clinical trial. JAMA Cardiol 2017;2:608-16. doi:10.1001/jamacardio.2017.0175

29 Zittermann A, Ernst JB, Prokop S, et al. Effect of vitamin D on allcause mortality in heart failure (EVITA): a 3-year randomized clinical trial with 4000 IU vitamin D daily. Eur Heart J 2017;38:2279-86. doi:10.1093/eurheartj/ehx235

30 Akiba T, Morikawa T, Odaka M, et al. Vitamin D supplementation and survival of patients with non-small cell lung cancer: a randomized, double-blind, placebo-controlled trial. Clin Cancer Res 2018;24:4089-97. doi:10.1158/1078-0432.CCR-18-0483

31 Manson JE, Cook NR, Lee IM, et al, VITAL Research Group. Vitamin D supplements and prevention of cancer and cardiovascular disease. $N$ Engl J Med 2019;380:33-44. doi:10.1056/NEJMoa1809944

32 Owusu JE, Islam S, Katumuluwa SS, et al. Cognition and vitamin $D$ in older African-American women: physical performance and osteoporosis prevention with vitamin D in older African Americans trial and dementia. J Am Geriatr Soc 2019;67:81-6. doi:10.1111/ jgs. 15607

33 Liberati A, Altman DG, Tetzlaff J, et al. The PRISMA statement for reporting systematic reviews and meta-analyses of studies that evaluate health care interventions: explanation and elaboration. Ann Intern Med 2009;151:W65-94. doi:10.7326/0003-4819-151-4200908180-00136

34 Richy F, Dukas L, Schacht E. Differential effects of D-hormone analogs and native vitamin $\mathrm{D}$ on the risk of falls: a comparative meta-analysis. Calcif Tissue Int 2008;82:102-7. doi:10.1007/s00223-008-9102-0

35 Shinichi A. Cochrane Handbook for Systematic Reviews of Interventions. Online Kensaku 2014;35:154-5.

36 Guyatt GH, Oxman AD, Vist GE, et al, GRADE Working Group. GRADE: an emerging consensus on rating quality of evidence and strength of recommendations. BMJ 2008;336:924-6. doi:10.1136/ bmj.39489.470347.AD

37 Higgins JP, Thompson SG. Quantifying heterogeneity in a metaanalysis. Stat Med 2002;21:1539-58. doi:10.1002/sim.1186

38 Egger M, Davey Smith G, Schneider M, Minder C. Bias in metaanalysis detected by a simple, graphical test. BMJ 1997;315:629-34. doi:10.1136/bmj.315.7109.629

39 Brok J, Thorlund K, Gluud C, Wetterslev J. Trial sequential analysis reveals insufficient information size and potentially false positive results in many meta-analyses. J Clin Epidemiol 2008;61:763-9. doi:10.1016/j.jclinepi.2007.10.007

40 Brohult J, Jonson B. Effects of large doses of calciferol on patients with rheumatoid arthritis. A double-blind clinical trial. Scand J Rheumatol 1973;2:173-6. doi:10.3109/03009747309097085

41 Inkovaara J, Gothoni G, Halttula R, Heikinheimo R, Tokola O. Calcium, vitamin D and anabolic steroid in treatment of aged bones: double-blind placebo-controlled long-term clinical trial. Age Ageing 1983;12:124-30. doi:10.1093/ageing/12.2.12

42 Corless D, Dawson E, Fraser F, et al. Do vitamin D supplements improve the physical capabilities of elderly hospital patients?Age Ageing 1985;14:76-84. doi:10.1093/ageing/14.2.76

43 Lips P, Graafmans WC, Ooms ME, Bezemer PD, Bouter LM Vitamin D supplementation and fracture incidence in elderly persons. A randomized, placebo-controlled clinical trial. Ann Intern Med 1996;124:400-6. doi:10.7326/0003-4819-124-4199602150-00003

44 Meyer HE, Smedshaug GB, Kvaavik E, Falch JA, Tverdal A, Pedersen II. Can vitamin $D$ supplementation reduce the risk of fracture in the elderly? A randomized controlled trial. J Bone Miner Res 2002;17:709-15. doi:10.1359/jbmr.2002.17.4.709

45 Bischoff HA, Stähelin HB, Dick W, et al. Effects of vitamin D and calcium supplementation on falls: a randomized controlled trial. J Bone Miner Res 2003;18:343-51. doi:10.1359/ jbmr.2003.18.2.343

46 Cooper L, Clifton-Bligh PB, Nery ML, et al. Vitamin D supplementation and bone mineral density in early postmenopausal women. Am J Clin Nutr 2003;77:1324-9. doi:10.1093/ajcn/77.5.1324

47 Latham NK, Anderson CS, Lee A, Bennett DA, Moseley A, Cameron IDFitness Collaborative Group. A randomized, controlled trial of quadriceps resistance exercise and vitamin $\mathrm{D}$ in frail older people: the Frailty Interventions Trial in Elderly Subjects (FITNESS). J Am Geriatr Soc 2003;51:291-9. doi:10.1046/j.1532-5415.2003.51101.x 
48 Trivedi DP, Doll R, Khaw KT. Effect of four monthly oral vitamin D3 (cholecalciferol) supplementation on fractures and mortality in men and women living in the community: randomised double blind controlled trial. BMJ 2003;326:469. doi:10.1136/ bmj.326.7387.469

49 Harwood RH, Sahota O, Gaynor K, Masud T, Hosking DJ, Nottingham Neck of Femur (NONOF) Study. A randomised, controlled comparison of different calcium and vitamin $\mathrm{D}$ supplementation regimens in elderly women after hip fracture: The Nottingham Neck of Femur (NONOF) Study. Age Ageing 2004;33:45-51. doi:10.1093/ageing/ afh002

50 Aloia JF, Talwar SA, Pollack S, Yeh J. A randomized controlled trial of vitamin D3 supplementation in African American women. Arch Intern Med 2005;165:1618-23. doi:10.1001/archinte.165.14.1618

51 Flicker L, MacInnis RJ, Stein MS, et al. Should older people in residential care receive vitamin D to prevent falls? Results of randomized trial. J Am Geriatr Soc 2005;53:1881-8. doi:10.1111/ j.1532-5415.2005.00468.x

52 Law M, Withers H, Morris J, Anderson F. Vitamin D supplementation and the prevention of fractures and falls: results of a randomised trial in elderly people in residential accommodation. Age Ageing 2006;35:482-6. doi:10.1093/ageing/afj080

53 Schleithoff SS, Zittermann A, Tenderich G, Berthold HK, Stehle $\mathrm{P}$, Koerfer R. Vitamin D supplementation improves cytokine profiles in patients with congestive heart failure: a double-blind, randomized, placebo-controlled trial. Am / Clin Nutr 2006;83:754-9. doi:10.1093/ajen/83.4.754

54 Broe KE, Chen TC, Weinberg J, Bischoff-Ferrari HA, Holick MF, Kiel DP. A higher dose of vitamin d reduces the risk of falls in nursing home residents: a randomized, multiple-dose study. I Am Geriatr Soc 2007; 55:234-9. doi:10.1111/j.1532-5415.2007.01048.x

55 Burleigh E, McColl J, Potter J. Does vitamin D stop inpatients falling? A randomised controlled trial. Age Ageing 2007;36:507-13. doi:10.1093/ageing/afm087

56 Lappe JM, Travers-Gustafson D, Davies KM, Recker RR, Heaney RP. Vitamin D and calcium supplementation reduces cancer risk: results of a randomized trial. Am J Clin Nutr 2007;85:1586-91. doi:10.1093/ajcn/85.6.1586

57 Lyons RA, Johansen A, Brophy S, et al. Preventing fractures among older people living in institutional care: a pragmatic randomised double blind placebo controlled trial of vitamin D supplementation. Osteoporos Int 2007;18:811-8. doi:10.1007/s00198-006-0309-5

58 Smith H, Anderson F, Raphael H, Maslin P, Crozier S, Cooper C. Effect of annual intramuscular vitamin D on fracture risk in elderly men and women--a population-based, randomized, double-blind, placebo-controlled trial. Rheumatology (Oxford) 2007;46:1852-7. doi:10.1093/rheumatology/kem240

59 Chel V, Wijnhoven HA, Smit JH, Ooms M, Lips P. Efficacy of differen doses and time intervals of oral vitamin D supplementation with or without calcium in elderly nursing home residents. Osteoporos Int 2008;19:663-71. doi:10.1007/s00198-007-0465-2

60 Prince RL, Austin N, Devine A, Dick IM, Bruce D, Zhu K. Effects of ergocalciferol added to calcium on the risk of falls in elderly high-risk women. Arch Intern Med 2008;168:103-8. doi:10.1001/ archinternmed.2007.31

61 Zhu K, Devine A, Dick IM, Wilson SG, Prince RL. Effects of calcium and vitamin D supplementation on hip bone mineral density and calciumrelated analytes in elderly ambulatory Australian women: a five-year randomized controlled trial. / Clin Endocrinol Metab 2008;93:743-9. doi:10.1210/jc.2007-1466

62 Janssen HC, Samson MM, Verhaar HJ. Muscle strength and mobility in vitamin D-insufficient female geriatric patients: a randomized controlled trial on vitamin D and calcium supplementation. Aging Clin Exp Res 2010;22:78-84. doi:10.1007/BF03324819

63 Lips P, Binkley N, Pfeifer M, et al. Once-weekly dose of 8400 IU vitamin $\mathrm{D}$ (3) compared with placebo: effects on neuromuscular function and tolerability in older adults with vitamin D insufficiency. Am J Clin Nutr 2010;91:985-91. doi:10.3945/ajcn.2009.28113

64 Sanders KM, Stuart AL, Williamson EJ, et al. Annual high-dose ora vitamin $\mathrm{D}$ and falls and fractures in older women: a randomized controlled trial. JAMA 2010;303:1815-22. . doi:10.1001/ jama.2010.594

65 Witham MD, Crighton $L$ Gillespie ND, Struthers AD, McMurdo ME. The effects of vitamin D supplementation on physical function and quality of life in older patients with heart failure: a randomized controlled trial. Circ Heart Fail 2010;3:195-201. doi:10.1161/ CIRCHEARTFAILURE.109.907899

66 Cherniack EP, Florez HJ, Hollis BW, Roos BA, Troen BR, Levis S. The response of elderly veterans to daily vitamin D3 supplementation of 2,000 IU: a pilot efficacy study. / Am Geriatr Soc 2011;59:286-90. doi:10.1111/j.1532-5415.2010.03242.x

67 Grimnes G, Figenschau Y, Almås B, Jorde R. Vitamin D, insulin secretion, sensitivity, and lipids: results from a case-control study and a randomized controlled trial using hyperglycemic clamp technique. Diabetes 2011;60:2748-57. doi:10.2337/db11-0650

68 Avenell A, MacLennan GS, Jenkinson DJ, et al, RECORD Trial Group. Long-term follow-up for mortality and cancer in a randomized placebo-controlled trial of vitamin D(3) and/or calcium (RECORD trial). J Clin Endocrinol Metab 2012;97:614-22. doi:10.1210/ jc.2011-1309

69 Glendenning P, Zhu K, Inderjeeth C, Howat P, Lewis JR, Prince RL. Effects of three-monthly oral 150,000 IU cholecalciferol supplementation on falls, mobility, and muscle strength in older postmenopausal women: a randomized controlled trial. J Bone Miner Res 2012;27:170-6. doi:10.1002/jbmr.524

70 Lehouck A, Mathieu C, Carremans C, et al. High doses of vitamin $D$ to reduce exacerbations in chronic obstructive pulmonary disease: a randomized trial. Ann Intern Med 2012;156:105-14. doi:10.7326/0003-4819-156-2-201201170-00004

71 Punthakee Z, Bosch J, Dagenais G, et al, TIDE Trial Investigators. Design, history and results of the Thiazolidinedione Intervention with vitamin D Evaluation (TIDE) randomised controlled trial. Diabetologia 2012;55:36-45. doi:10.1007/s00125-011-2357-4

72 Witham MD, Price RJ, Struthers AD, et al. Cholecalciferol treatment to reduce blood pressure in older patients with isolated systolic hypertension: the VitDISH randomized controlled trial. JAMA Intern Med 2013;173:1672-9. doi:10.1001/jamainternmed.2013.9043

73 Ott SM, Chesnut CH3rd. Calcitriol treatment is not effective in postmenopausal osteoporosis. Ann Intern Med 1989;110:267-74. doi:10.7326/0003-4819-110-4-267

74 Grady D, Halloran B, Cummings S, et al. 1,25-Dihydroxyvitamin D3 and muscle strength in the elderly: a randomized controlled trial. J Clin Endocrinol Metab 1991;73:1111-7. doi:10.1210/jcem-73-51111

75 Sato Y, Maruoka H, Oizumi K. Amelioration of hemiplegia-associated osteopenia more than 4 years after stroke by 1 alpha-hydroxyvitamin D3 and calcium supplementation. Stroke 1997;28:736-9. doi:10.1161/01.STR.28.4.736

76 Sato Y, Kuno H, Kaji M, Saruwatari N, Oizumi K. Effect of ipriflavone on bone in elderly hemiplegic stroke patients with hypovitaminosis D [retracted]. Am J Phys Med Rehabil 1999;78:457-63. doi:10.1097/00002060-199909000-00008

77 Sato Y, Manabe S, Kuno H, Oizumi K. Amelioration of osteopenia and hypovitaminosis D by 1alpha-hydroxyvitamin D3 in elderly patients with Parkinson's disease. J Neurol Neurosurg Psychiatry 1999;66:648. doi:10.1136/jnnp.66.1.64

78 Gallagher JC, Fowler SE, Detter JR, Sherman SS. Combination treatment with estrogen and calcitriol in the prevention of age-related bone loss. J Clin Endocrinol Metab 2001;86:3618-28. doi:10.1210/ jcem.86.8.7703

79 Dukas L, Bischoff HA, Lindpaintner LS, et al. Alfacalcidol reduces the number of fallers in a community-dwelling elderly population with a minimum calcium intake of more than 500 mg daily. J Am Geriatr Soc 2004;52:230-6. doi:10.1111/j.1532-5415.2004.52060.x

80 Sato Y, Iwamoto J, Kanoko T, Satoh K. Low-dose vitamin D prevents muscular atrophy and reduces falls and hip fractures in women after stroke: a randomized controlled trial [retracted]. Cerebrovasc Dis 2005;20:187-92. doi:10.1159/000087203

81 Bjelakovic G, Gluud LL, Nikolova D, et al. Vitamin D supplementation for prevention of cancer in adults. Cochrane Database Syst Rev 2014;(6):CD007469. doi:10.1002/14651858.CD007469. pub2

82 Keum N, Giovannucci E. Vitamin D supplements and cancer incidence and mortality: a meta-analysis. Br J Cancer 2014;111:976-80. doi:10.1038/bjc.2014.294

83 Goulão B, Stewart F, Ford IA, MacLennan G, Avenell A. Cancer and vitamin D supplementation: a systematic review and meta-analysis. Am J Clin Nutr 2018;107:652-63. doi:10.1093/ajcn/nqx047

84 Keum N, Lee DH, Greenwood DC, Manson JE, Giovannucci E Vitamin D supplementation and total cancer incidence and mortality: a metaanalysis of randomized controlled trials. Ann Oncol 2019;30:733-43. doi:10.1093/annonc/mdz059

85 Tripkovic L, Lambert H, Hart K, et al. Comparison of vitamin D2 and vitamin D3 supplementation in raising serum 25 -hydroxyvitamin D status: a systematic review and meta-analysis. Am J Clin Nutr 2012;95:1357-64. doi:10.3945/ajcn.111.031070

86 Wilson LR, Tripkovic L, Hart KH, Lanham-New SA. Vitamin D deficiency as a public health issue: using vitamin D2 or vitamin D3 in future fortification strategies. Proc Nutr Soc 2017;76:392-9. doi:10.1017/ S0029665117000349

87 JPT Higgins SGE. The Cochrane Handbook for Systematic Reviews of Interventions. The Cochrane Collaboration, Oxford 2011; version 5.1.0

Web appendix: Supplemental e-material 